\title{
An Empirical Evaluation of Different Electronic Payment Channels in Nigeria
}

\author{
Fidelis Onyemaechi Nedozi ${ }^{1}$, Chris Ikponmwen Omoregie ${ }^{2}$ \\ ${ }^{1}$ Department of Business Administration, School of Higher Education, Institute of Continuing Education, Benin City, Nigeria \\ ${ }^{2}$ Department of Computer Science, College of Education, Ekiadolor, Benin City, Nigeria
}

Email address:

Knoph4u@yahoo.com (F. O. Nedozi),desmondikponmwen@gmail.com (C. I. Omoregie)

\section{To cite this article:}

Fidelis Onyemaechi Nedozi, Chris Ikponmwen Omoregie. An Empirical Evaluation of Different Electronic Payment Channels in Nigeria. Journal of Finance and Accounting. Special Issue: Financial Inclusion, Accounting Perspectives and Development.

Vol. 7, No. 5, 2019, pp. 146-152. doi: 10.11648/j.jfa.20190705.13

Received: August 30, 2019; Accepted: September 17, 2019; Published: September 29, 2019

\begin{abstract}
Payments system plays a very crucial role in any economy, being the channel through which financial resources flow from one segment of the economy to the other. This study has tried to empirically evaluate the electronic-payment channels and their penetration level in Nigeria from 2012 to first quarter of 2019. The main research objective was to determine given the technology revolution the level of e-payment penetration in Nigeria. Concepts of e-payment, E-payment in Nigeria and the different E-payment platforms were reviewed. The data were obtained from the secondary sources like CBN, journals, and commercial banks quarterly bulletins. The study employed descriptive statistics to ascertain the level of penetration E-payment in Nigeria. The data were analyzed using percentages. From the study, it was found that ATM dominated the penetration of E-payment in terms of volume in Nigeria from 2011 to first quarter of 2019. In terms of value NEFT dominated in 2012 and 2013 while NIP dominated from 2014 to first quarter of 2019. It is recommended that more electronic channels should be open to deepen the electronic transactions in the economy to fast tract transaction as the world move into tech revolution. Also, the issue of fraud emanating from electronic transaction should be checked and reduce to give trust to consumers of such transactions.
\end{abstract}

Keywords: Payment. Electronic, Cheque, Cash, Money

\section{Introduction}

The payments system plays a very crucial role in any economy, being the channel through which financial resources flow from one segment of the economy to the other. It, therefore, represents the major foundation of the modern market economy. Payment system according to Ojo [1], can be viewed as an arrangement consisting of institutions, instruments, organizations, operating procedures, and information and communication systems, usually within a nation's financial system, used to initiate and transmit payment information from payer to payee and to settle payment or discharge financial obligation among economic units. Payment systems may be physical or electronic and each has its own procedures and protocols. [2]

Payment systems or methods are very many in a modern day business. They include but not limited to cash, cheque, credit or debit cards, money order, bank transfer and online payment services such as PayPal, EPOS which is a selfcontrolled, computerized equipment that performs all tasks of a store, checkout counter, it allows payment by bank or credit cards, verifies transactions, provide sales reports, coordinates inventory data, and performs several other services normally provided by employees.

Kelvin [3] declared that the introduction of technology based payments systems has done a lot to increase the convenience of bank's customers, staff as well as the society at large. Nigeria is lagging way behind most of the world in the general quest to boost micro economic activity by reducing the role played by physical cash in daily transactions and by encouraging the creation of cashless society, this can be averted [4]. In Nigeria, there are different payment systems and the focus of this article, is the analysis of different methods or systems of e-payment with a view to exposing the penetration level of the different methods or systems. 


\section{Literature Review}

\subsection{Electronic Payment}

Electronic payment which is also called online payment, is a payment option that completely exclude the use of cash and cheque. It is a non cash system which uses electronic media such as credit card, debit card and the automated clearing house $(\mathrm{ACH})$ network. It requires customer action, payment authentication and payment to accounts. It is considered to be fast or time saving, control expenses, convenient, user friendly but faced with challenges which includes restrictions in terms of the number of transactions per day, in some cases but generally with limited amount per day, the risk of hacking, lack of anonymity and the need for internet access among others.

\subsection{Electronic Payment in Nigeria}

Electronic payment can be said to be relatively new in Nigeria as compared to some other countries especially those referred to as developed. The use of cash or cheque as payment option, is still popular especially in petty transactions with petty traders and artisans. Poor awareness of e-payment solutions, ignorance, poor banking culture, lack of trust, illiteracy and the love for the status quo has been fingered as responsible for the volume of cash transactions in Nigeria [5].

Ayodele [6] observed that constant power failure has led to deficiencies in infrastructures such as ATMs, computers etc. which slow down the rate of electronic transaction. Frequent failure of network from communication service providers in Nigeria too has been a major challenge to e-banking vis a vis e-payment.

Oladayo, T. \& Adeniyi [7] observed that the unreconciled interbank transactions are compounding the uses of ATM. ATM users' are often face with issues of being debited sometimes when the machine did not dispense cash and reversal sometimes take time especially when it is interbank transactions. Possessing ATM card and its password has proven not to be a sufficient proof of ownership because fraudsters have found a way ground it. It is a known fact that for so many years, the use of cheque has been the main option to cash in Nigeria. Cheques have not been generally acceptable to sellers especially petty traders. Cases of bounce or dud cheques and mistrust have hindered its acceptance by even big merchants. This is not unconnected with lack of electronic means of ascertaining the validity of cheques until they are presented at banks. Although the central bank of Nigeria $(\mathrm{CBN})$, has introduced inter-bank electronic cheque clearing system, the effort of CBN has only reduced the time of verification and redemption of cheques thus far, making cash payment, the most credible and general accepted means.

Okafor [5] averred that a payment system that can replace or compete with cash, must win the trust of merchants in the economy. This he said can only happen, if there is a way the merchants can verify the validity of the purchases, the payment solutions must also be easily convertible to cash or as good as cash, since most merchants in Nigeria are in business on subsistence basis. E-payment or e-transactions solutions will play a role here, however, it has not gained much ground.

\subsection{Means of Electronic Payment}

\subsubsection{Automated Teller Machine (ATM)}

Ayodele [8] described ATM card as a chip device consisting of circuit's elements on single silicon chip, used by customers to perform balances, inquiry, mini-statements and cash withdrawal as well as transfer, through the use of automated teller machines. Okafor [9] perceives the ATM as an electronic device which allows a financial institution customer to use a secure method of communication to access their accounts, make cash withdrawals or cash advances using credit cards and checking their account balances without need for human teller or cashier.

It is adjudged to be the most popular e-transactions means in Nigeria especially with the introduction of Point of Sale (POS) terminals. It is convenient, easy to withdraw cash, make payments, make transfers and even check account balances. However, it has not done much in reducing the volume of cash in the Nigeria economy. These services are provided by Inters witch, Vpay, Quick cash etc in Nigeria.

\subsubsection{Point of Sales (POS) Terminal}

The use of POS terminal (machine) has greatly reduced the use of cash for transactions. Ayodele [6] also described it as a payment device that allows credit/debit cardholders makes payment at sales/purchase outlets. It allows customers to perform services inquiry, airtime, vending, loyalty, redemption and printing of mini statement. [10]

\subsubsection{Credit or Debit Cards and E-Wallets}

Credit or debit cards and e-wallets makes shopping cashless. Unlike the ATM, credit cards, debit cards and ewallets will help the Central Bank of Nigeria (CBN), to achieve the cashless policy. Credit and debit cards use Point of Sales (POS) terminals located at accredited retail outlets. However, most ATM cards in Nigeria, also serve as both credit and debit cards. [10]

\subsubsection{Internet Fund Transfer}

Is it the use of internet by a customer to send money from his/her account to another account and/or back. The customer requires an internet enable computer or phone to carry out the fund transfer. It is fast and convenient but could be hindered by network failure. Examples include Central Bank of Nigeria Real Time Gross Settlement System (RTGS), Western Union Money Transfer etc.

\subsubsection{Nigeria Interbank Settlement System (NEFT)}

The Nigeria Interbank Settlement System (NIBSS) electronic fund transfer is an irrevocable funds transfer instruction. The user logs into his/her bank's internet banking platform using his/her ID and Password. He or she would go to fund transfer tab and enter the necessary details of the receiver in terms of bank, account number and amount and click send. NEFT can be useful to transfer fund to many recipients at the same time, but the receiver get (s) the value sometimes in 24 hours. 


\subsubsection{NIBSS Instant Payment}

It is a transfer option which can be used to transfer money from one customer's account to any bank account in Nigeria. NIP can only be used to transfer money to one or two persons at the same time but the transfer is instantaneous because the receiver gets value within minutes.

\subsubsection{NIBSS Automated Payment Services (NAP)}

It is an integrated multibank e-payment, e-collection and payroll and bulk payment platform. By its design, it is suitable for instant processing of payroll, pension, personnel records and execution of funds transfer, direct debit, collections, schedule delivery and payment instruction, but could be hindered by the availability of network.

\subsubsection{Mobile Payment}

Mobile payment refers to payment services operated under financial regulations and it is performed using mobile devices. Its models include mobile wallets, card-based payments, carrier billing, contactless payments and direct transfer between payer and payee bank account. It is fast and convenient but depends on availability of network. [10]

\subsubsection{Remita}

Remita is a solution that addresses the payment needs of individuals and organizations. It was developed by FinTech Systemspecs. It helps to receive and make payment easily without activation fee. It is secure and has Human Resource (HR) and payroll functions. It is actually an innovative way to manage electronic payments, collections, employees payrolls and schedules. There is Remita Personal and Remita for corporate users. It protects user's data with multiple security protocols but requires internet connection.

\subsubsection{Others Are}

NIBSS e-Billspay

It is an account-based, online real-time product that facilitates the payment of bills from an account. It ensures instant credit of payments and receipt of collections on behalf of Billers/Merchant recruited on the platform.

Mobile Money

Mobile Money is a payment solution that enables buyers pay for goods and services with their mobile phones. Mobile Money is one of the e-payment solutions available to Nigerians. It is at the core of the CBN's cashless Nigeria policy. These services are provided in Nigeria by:

PocketMoni, Paga, QikQik, GTBank 737, MTN Mobile Money, U-Mo, Stanbic 909, EazyMoney, Glo Mobile Money amongst others.
Automated Clearing House (ACH) \& Periodic Monthly Statement (PMS)

The Automated Clearing House $(\mathrm{ACH})$ is an electronic payment option that allows participants to pay Customs duties, taxes, and fees electronically. ACH allows importers to pay duties with one electronic transaction in a secure environment. ACH fulfills the need for swift, accurate payment transfers in today's competitive business environment. It reduces administrative and check processing cost

PMS

Allows importers deposit duties on the 15 th business day of the month following the month in which the goods are released. It means merchandise released on the first to the last day of the month can be scheduled for duty payment on the following month's Periodic Monthly Statement. This eliminates the need to process duty payments on a transaction by transaction basis. Customs does not assess any interest charges for payments made via PMS. A user can have a once a month, interest free duty payment.

Web Payment

Web payment service is an online service that manages the transfer of funds from a customer to the merchant of an ecommerce website. The money may come from a prepaid account or credit card stored in a digital wallet in the user's device or stored in the service's datacenter. [11]

NIBSS Central Payment

NIBSS Central payment gateway is an e-commerce application service solution. CentralPay is a payment gateway application developed by NIBSS. With CentralPay, web merchants can easily receive payments online from their customers in exchange for goods and services. The unstable network situation affects its usage.

\section{M-Cash}

This is an innovative solution designed to facilitate lowvalue retail payments, grow e-payments by providing accessible electronic channels to a wider range of users and to further enhance financial inclusion in Nigeria, by extending e-payment benefits to Payers and Merchants. The unreliable nature of network hinders its usage too.

\section{Methodology}

To analyze the data obtained from the secondary sources like CBN, Journals, commercial banks quarterly bulletins the study employed descriptive statistics to ascertain the level of penetration e-payment in Nigeria. The data were analyzed using percentages.

\section{Data Presentation and Analysis}

Table 1. 2012 Distribution.

\begin{tabular}{llllll}
\hline channel & NEFT & ATM & POS & Internet (Web) & Mobile Money \\
\hline volume & $28,941,559$ & $375,513,154$ & $2,587,595$ & $2,276,464$ & $2,297,688$ \\
$\%$ & 6.96 & 90.25 & 0.62 & 0.55 & 0.55 \\
value & $13,753,178,360,585$ & $1,984,990,636,830$ & $48,461,883,431$ & $31,567,364,087$ & $31,509,334,783$ \\
$\%$ & 69.67 & 10.06 & 0.25 & 0.16 & 0.16 \\
\hline
\end{tabular}


Table 1. Continued.

\begin{tabular}{llllllll}
\hline channel & NIP & EBillsPay & Remita & M-CASH & Central Pay & NAPS & Total \\
\hline volume & $4,449,654$ & 0 & 0 & 0 & 0 & 0 & $416,066,114$ \\
$\%$ & 1.07 & 0.00 & 0.00 & 0.00 & 0.00 & 0.00 & 100.00 \\
value & $3,890,260,230,695$ & 0 & 0 & 0 & 0 & 0 & $19,739,967,810,411$ \\
$\%$ & 19.71 & 0.00 & 0.00 & 0.00 & 0.00 & 0.00 & 100.00 \\
\hline
\end{tabular}

Sources: Researchers" computation 2019, and National Bureau of Statistics [12]

The result table 1 indicates that by volume ATM has the highest volume of penetration or usage while Internet and Mobile Money have the least. A breakdown of the statistics shows that NEFT has $6.96 \%$, ATM has $90.25 \%$, POS has $0.62 \%$, Internet and Mobile Money have $0.55 \%$ each and NIP has $1.07 \%$. EBillsPay, Remita, M-Cash, Central Pay and NAPS were not in use.
For value, NEFT has the highest while Internet and Mobile Money have the least. A breakdown of the statistics shows that NEFT has $69.67 \%$, ATM has $10.06 \%$, POS has $0.25 \%$, Internet and Mobile Money have $0.16 \%$ each and NIP has 19.17\%. EBillsPay, Remita, M-Cash, Central Pay and NAPS were not in use.

Table 2. 2013 Distribution.

\begin{tabular}{|c|c|c|c|c|c|}
\hline channel & NEFT & ATM & POS & Internet (Web) & Mobile Money \\
\hline volume & $29,834,317$ & $295,416,724$ & $9,418,427$ & $2,900,473$ & $15,930,181$ \\
\hline$\%$ & 8.05 & 79.71 & 2.54 & 0.78 & 4.30 \\
\hline value & $14,367,950,496,617$ & $2,830,533,105,570$ & $161,212,840,665$ & $47,316,331,494$ & $143,371,761,235$ \\
\hline$\%$ & 50.59 & 9.97 & 0.57 & 0.17 & 0.50 \\
\hline
\end{tabular}

Table 2. Continued.

\begin{tabular}{lllllll}
\hline channel & NIP & EBillsPay & Remita & M-CASH & Central Pay & NAPS \\
\hline volume & $17,112,158$ & 557 & 0 & 0 & 0 & 0 \\
$\%$ & 4.62 & 0.00 & 0.00 & 0.00 & 0.00 & 0.00 \\
value & $10,848,734,178,263$ & $15,419,049.00$ & 0 & 0 & 0 & 0 \\
$\%$ & 38.20 & 0.00 & 0.00 & 0.00 & 0.00 & 0.00 \\
\hline
\end{tabular}

Sources: Researchers" computation 2019 and National Bureau of Statistics [13]

The result table 2 indicates that by volume ATM has the highest volume of penetration or usage while EBillsPay has the least. A breakdown of the statistics shows that NEFT has $8.05 \%$, ATM has $79.71 \%$, POS has $2.54 \%$, Internet has $0.78 \%$, Mobile Money has $4.30 \%$, NIP has $4.62 \%$. EBillsPay, has less than $0.1 \%$ Remita, M-Cash, Central Pay and NAPS were not in use.
For value, NEFT has the highest while EBillsPay has the least. A breakdown of the statistics shows that NEFT has $50.59 \%$, ATM has $9.97 \%$, POS has $0.57 \%$, Internet has $0.17 \%$, Mobile Money has $0.50 \%$, NIP has $38.20 \%$. EBillsPay, has less than $0.1 \%$ and Remita, M-Cash, Central Pay and NAPS were not in use.

Table 3. 2014 Distribution.

\begin{tabular}{lllll}
\hline channel & NEFT & ATM & POS & Internet (Web) \\
\hline volume & $29,690,765$ & $400,269,140$ & $20,817,423$ & $5,567,436$ \\
$\%$ & 5.49 & 74.05 & 3.85 & 1.03 \\
value & $14,563,804,544,654$ & $3,681,980,955,458$ & $312,071,736,903$ & $74,205,599,261$ \\
$\%$ & 33.21 & 8.40 & 0.71 & 5.13 \\
\hline
\end{tabular}

Table 3. Continued.

\begin{tabular}{|c|c|c|c|c|c|c|c|}
\hline channel & NIP & EBillsPay & Remita & M-CASH & Central Pay & NAPS & Total \\
\hline volume & $40,829,854$ & 593,579 & $15,029,627$ & 0 & 0 & 0 & $540,542,621$ \\
\hline$\%$ & 7.55 & 0.11 & 2.78 & 0.00 & 0.00 & 0.00 & 100.00 \\
\hline value & $19,921,499,572,670$ & $44,334,722,247.00$ & $4,914,138,084,329.72$ & 0 & 0 & 0 & $43,851,272,048,490$ \\
\hline$\%$ & 33.21 & 8.40 & 0.71 & 0.17 & 0.77 & 45.43 & 0.10 \\
\hline
\end{tabular}

Sources: Researchers" computation 2019 and National Bureau of Statistics [13]

The result table 3 indicates that by volume ATM has the highest volume of penetration or usage while EBillsPay has the least. A breakdown of the statistics shows that NEFT has 5.49\%, ATM has $74.05 \%$, POS has $3.85 \%$, Internet has $1.03 \%$, Mobile Money has 5.13\%, NIP has 7.55\%. EBillsPay, has $0.11 \%$ Remita, has $2.78 \%$ and M-Cash, Central Pay and NAPS were not in use.
For value, NIP has the highest while EBillsPay has the least. A breakdown of the statistics shows that NEFT has $33.21 \%$, ATM has $8.40 \%$, POS has $0.71 \%$, Internet has $0.17 \%$, Mobile Money has $0.77 \%$, NIP has $45.43 \%$. EBillsPay, has $0.10 \%$, Remita, has $11.21 \%$ and M-Cash, Central Pay and NAPS were not in use. 
Table 4. 2015 Distribution.

\begin{tabular}{lllllll}
\hline channel & NEFT & ATM & POS & Internet (Web) & Mobile Money & NIP \\
\hline volume & $28,935,605$ & $433,695,748$ & $33,720,933$ & $7,981,361$ & $43,933,362$ & $71,223,545$ \\
$\%$ & 4.51 & 67.65 & 5.26 & 1.24 & 6.85 & 11.11 \\
value & $13,087,085,484,769$ & $3,971,651,486,420$ & $448,512,548,727$ & $91,581,292,533$ & $442,353,763,489$ & $25,540,842,563,780$ \\
$\%$ & 26.11 & 7.92 & 0.89 & 0.18 & 0.88 & 50.96 \\
\hline
\end{tabular}

Table 4. Continued.

\begin{tabular}{lllllll}
\hline channel & EBillsPay & Remita & M-CASH & Central Pay & NAPS & Total \\
\hline volume & $1,208,556$ & $19,417,371$ & 0 & 66,031 & 936,667 & $641,119,179$ \\
$\%$ & 0.19 & 3.03 & 0.00 & 0.01 & 0.15 & 100.00 \\
value & $217,426,481,827.00$ & $6,223,453,782,841.90$ & 0 & $311,550,330.00$ & $98,684,511,448.00$ & $50,121,903,466,165$ \\
$\%$ & 0.43 & 12.42 & 0.00 & 0.00 & 0.20 & 100.00 \\
\hline
\end{tabular}

Sources: Researchers" computation 2019 and National Bureau of Statistics [13]

The result table 4 indicates that by volume ATM has the highest volume of penetration or usage while Central Pay has the least. A breakdown of the statistics shows that NEFT has $4.51 \%$, ATM has $67.65 \%$, POS has $5.26 \%$, Internet has $1.24 \%$, Mobile Money has $6.85 \%$, NIP has $11.11 \%$. EBillsPay, has $0.19 \%$ Remita, has $3.03 \%$ and M-Cash, not in use, Central Pay has $0.01 \%$, and NAPS 0.15\%.
For value, NIP has the highest while Central Pay has the least. A breakdown of the statistics shows that NEFT has $26.11 \%$, ATM has $7.92 \%$, POS has $0.89 \%$, Internet has $0.18 \%$, Mobile Money has $0.88 \%$, NIP has $50.96 \%$. EBillsPay, has $0.43 \%$, Remita, has $12.42 \%$ and M-Cash, not in use, Central Pay has less than $0.1 \%$ and NAPS has $0.20 \%$.

Table 5. 2016 Distribution.

\begin{tabular}{|c|c|c|c|c|c|c|}
\hline channel & NEFT & ATM & POS & Internet (Web) & Mobile Money & NIP \\
\hline volume & $29,754,182$ & $590,238,934$ & $63,715,203$ & $14,088,247$ & $47,053,252$ & $153,616,450$ \\
\hline$\%$ & 3.16 & 62.67 & 6.77 & 1.50 & 5.00 & 16.31 \\
\hline value & $14,584,802,657,086$ & $4,988,133,401,544$ & $758,996,505,702$ & $132,360,333,369$ & $756,897,483,653$ & $38,109,061,203,852$ \\
\hline$\%$ & 20.52 & 7.02 & 1.07 & 0.19 & 1.06 & 53.62 \\
\hline
\end{tabular}

Table 5. Continued.

\begin{tabular}{lllllll}
\hline channel & EBillsPay & Remita & M-CASH & Central Pay & NAPS \\
\hline volume & $1,026,886$ & $38,249,886$ & 0 & 70,239 & $3,965,212$ \\
$\%$ & 0.11 & 4.06 & 0.00 & 0.01 & 0.42 \\
value & $339,407,748,303.63$ & $10,652,493,933,099.30$ & 0 & $1,442,064,836.87$ & $753,689,705,802.99$ & $71,077,285,037,249$ \\
$\%$ & 0.48 & 14.99 & 0.00 & 0.00 & 100.00 \\
\hline
\end{tabular}

Sources: Researchers" computation 2019, Central Bank of Nigeria [14] and National Bureau of Statistics [13]

The result table 5 indicates that by volume ATM has the highest volume of penetration or usage while Central Pay has the least. A breakdown of the statistics shows that NEFT has $3.16 \%$, ATM has $62.67 \%$, POS has $6.77 \%$, Internet has $1.50 \%$, Mobile Money has $5.00 \%$, NIP has $16.31 \%$. EBillsPay, has $0.11 \%$ Remita, has $4.06 \%$ and M-Cash, not in use, Central Pay has $0.01 \%$, and NAPS $0.42 \%$.
For value, NIP has the highest while central pay has the least. A breakdown of the statistics shows that NEFT has $20.52 \%$, ATM has $7.02 \%$, POS has $1.07 \%$, Internet has $0.19 \%$, Mobile Money has $1.06 \%$, NIP has $53.62 \%$. EBillsPay, has $0.48 \%$, Remita, has $14.99 \%$ and M-Cash, not in use, Central Pay has less than $0.1 \%$ and NAPS has $1.06 \%$.

Table 6. 2017 Distribution

\begin{tabular}{lllllll}
\hline channel & NEFT & ATM & POS & Internet (Web) & Mobile Money & NIP \\
\hline volume & $31,034,624$ & $800,549,099$ & $146,267,156$ & $28,991,097$ & $47,804,561$ & $370,870,672$ \\
$\%$ & 2.10 & 54.15 & 9.89 & 1.96 & 3.23 & 25.08 \\
value & $14,946,463,879,672.40$ & $6,437,592,402,748.64$ & $1,409,813,091,608.35$ & $184,596,629,926.57$ & $1,101,998,974,555.00$ & $56,165,666,312,858.10$ \\
$\%$ & 15.05 & 6.48 & 1.42 & 0.19 & 1.11 & 56.57 \\
\hline
\end{tabular}

Table 6. Continued

\begin{tabular}{llllll}
\hline channel & EBillsPay & Remita & M-CASH & Central Pay & NAPS \\
\hline volume & 905,941 & $39,706,264$ & 77,832 & 375,356 & $11,900,008$ \\
$\%$ & 0.06 & 2.69 & 0.01 & 0.03 & 0.80 \\
\hline
\end{tabular}




\begin{tabular}{llllll}
\hline channel & EBillsPay & Remita & M-CASH & Central Pay & NAPS \\
\hline value & $550,750,791,543.15$ & $13,529,495,515,408.40$ & $616,936,468.57$ & $4,996,845,611.06$ & $4,960,349,089,466.59$ \\
$\%$ & 0.55 & 13.63 & 0.00 & 0.01 & 5.00 \\
\hline
\end{tabular}

Sources: Researchers" computation 2019, Central Bank of Nigeria [14] and National Bureau of Statistics [15]

The result table 6 indicates that by volume ATM has the highest volume of penetration or usage while M-Cash has the least. A breakdown of the statistics shows that NEFT has $2.10 \%$, ATM has $54.15 \%$, POS has $9.89 \%$, Internet has $1.96 \%$, Mobile Money has $3.23 \%$, NIP has $25.08 \%$. EBillsPay, has $0.06 \%$ Remita, has $2.69 \%$ and M-Cash, 0.01 , Central Pay has $0.03 \%$, and NAPS $0.80 \%$.
For value, NIP has the highest while M-Cash has the least. A breakdown of the statistics shows that NEFT has $15.05 \%$, ATM has $6.48 \%$, POS has $1.42 \%$, Internet has $0.19 \%$, Mobile Money has $1.11 \%$, NIP has $56.57 \%$. EBillsPay, has $0.55 \%$, Remita, has $13.63 \%$ and M-Cash, less than $0.01 \%$, Central Pay has less than $0.1 \%$ and NAPS has $5.00 \%$.

Table 7. 2018 Distribution.

\begin{tabular}{|c|c|c|c|c|c|c|}
\hline channel & NEFT & ATM & POS & Internet (Web) & Mobile Money & NIP \\
\hline volume & $26,760,852$ & $875,519,307$ & $295,890,167$ & $50,815,901$ & $87,086,260$ & $663,124,139$ \\
\hline$\%$ & 1.29 & 42.22 & 14.27 & 2.45 & 4.20 & 31.98 \\
\hline value & $11,030,961,545,925.40$ & $6,480,085,899,670.37$ & $2,383,108,901,148.12$ & $404,600,990,712.52$ & $1,830,701,111,107.85$ & $80,423,025,698,377.30$ \\
\hline$\%$ & 8.25 & 4.85 & 1.78 & 0.30 & 1.37 & 60.18 \\
\hline
\end{tabular}

Table 7. Continued.

\begin{tabular}{llllll}
\hline channel & EBillsPay & Remita & M-CASH & Central Pay & NAPS \\
\hline volume & $1,053,342$ & $44,461,846$ & 229,328 & $1,260,380.00$ & $27,384,756$ \\
$\%$ & 0.05 & 2.14 & 0.01 & 0.06 & 1.32 \\
value & $500,214,507,607.64$ & $18,495,987,427,570.80$ & $1,198,731,322.12$ & $8,101,555,613.41$ & $12,078,905,639,559.80 \quad 133,636,892,008,615$ \\
$\%$ & 0.37 & 13.84 & 0.00 & 0.01 & 9.04 \\
\hline
\end{tabular}

Sources: Researchers" computation 2019, Central Bank of Nigeria [14], First Bank of Nigeria [16] and National Bureau of Statistics [15]

The result table 7 indicates that by volume ATM has the highest volume of penetration or usage while M-Cash has the least. A breakdown of the statistics shows that NEFT has $1.29 \%$, ATM has $42.22 \%$, POS has $14.27 \%$, Internet has $2.45 \%$, Mobile Money has $4.20 \%$, NIP has $31.98 \%$. EBillsPay, has $0.05 \%$ Remita, has $2.14 \%$ and M-Cash, 0.01 , Central Pay has $0.06 \%$, and NAPS $1.32 \%$.
For value, NIP has the highest while M-Cash has the least. A breakdown of the statistics shows that NEFT has $8.25 \%$, ATM has $4.85 \%$, POS has $1.78 \%$, Internet has $0.30 \%$, Mobile Money has $1.37 \%$, NIP has $60.18 \%$. EBillsPay, has $0.37 \%$, Remita, has $13.84 \%$ and M-Cash, less than $0.01 \%$, Central Pay has $0.1 \%$ and NAPS has $9.04 \%$.

Table 8. First qtr. of 2019 Distribution.

\begin{tabular}{|c|c|c|c|c|c|c|}
\hline channel & ACH/NAPS/PMS & ATM & POS & Internet (Web) & Mobile Money & NIP \\
\hline volume & $10,695,439$ & $202,959,732$ & $53,941,390$ & $20,382,111$ & $2,928,797$ & $232,816,102$ \\
\hline$\%$ & 2.03 & 38.62 & 10.26 & 3.88 & 0.56 & 44.30 \\
\hline value & $4,223,504,041,564$ & $1,539,265,918,383.52$ & $633,805,669,960.24$ & $7,644,819,814.25$ & $100,690,441,641.00$ & $15,583,268,191,734.70$ \\
\hline$\%$ & 19.06 & 6.95 & 2.86 & 0.03 & 0.45 & 70.34 \\
\hline
\end{tabular}

Table 8. Continued.

\begin{tabular}{|c|c|c|c|c|c|}
\hline channel & EBillsPay & Remita & M-CASH & Central Pay & Total \\
\hline volume & 227,969 & $1,463,013$ & 36,583 & $146,274.00$ & $525,597,410$ \\
\hline$\%$ & 0.04 & 0.28 & 0.01 & 0.03 & 100.00 \\
\hline value & $44,947,715,322.00$ & $19,253,402,486.23$ & $116,035,593.00$ & $1,093,744,957.95$ & $22,153,589,981,457$ \\
\hline$\%$ & 0.20 & 0.09 & 0.00 & 0.00 & 100.00 \\
\hline
\end{tabular}

Sources: Researchers" computation 2019, Central Bank of Nigeria [14] and National Bureau of Statistics [15]

The result table 8 indicates that by volume NIP has the highest volume of penetration or usage while M-Cash has the least. A breakdown of the statistics shows that ACH/NAPS/PMS has $2.03 \%$, ATM has $38.62 \%$, POS has $10.26 \%$, Internet has $3.88 \%$, Mobile Money has $0.56 \%$, NIP has $44.30 \%$. EBillsPay, has $0.04 \%$ Remita, has $0.28 \%$ and M-Cash, 0.01, and Central Pay has 0.03\%.

For value, NIP has the highest while M-Cash and central money have the least. A breakdown of the statistics shows that ACH/NAPS/PMS has $19.06 \%$, ATM has $6.95 \%$, POS has $2.86 \%$, Internet has $0.03 \%$, Mobile Money has $0.45 \%$, NIP has $70.34 \%$. EBillsPay, has $0.20 \%$, Remita, has $0.09 \%$ and M-Cash, less than $0.01 \%$, and Central Pay has less than $0.1 \%$. 


\section{Findings and Conclusion}

The result study shows that in 2012, by volume ATM has the highest volume of penetration or usage while internet and mobile money have the least. And by value, NEFT has the highest while internet and mobile money have the least. In 2013, by volume ATM has the highest volume of penetration or usage while EBillsPay has the least. For value, NEFT has the highest while EBillsPay has the least. In 2014, by volume ATM has the highest volume of penetration or usage while EBillsPay has the least. For value, NIP has the highest while EBillsPay has the least. In 2015, by volume ATM has the highest volume of penetration or usage while Central Pay has the least. For value, NIP has the highest while Central Pay has the least. In 2016, by volume ATM has the highest volume of penetration or usage while Central Pay has the least. For value, NIP has the highest while central pay has the least. In 2017, by volume ATM has the highest volume of penetration or usage while M-cash has the least. For value, NIP has the highest while M-Cash has the least. In 2018, by volume ATM has the highest volume of penetration or usage while M-cash has the least. For value, NIP has the highest while M-Cash has the least. In 2019 first quarter, by volume NIP has the highest volume of penetration or usage while Mcash has the least. For value, NIP has the highest while MCash and central money have the least.

From the study, it is clear that ATM dominated the penetration of E-payment in terms of volume in Nigeria from 2011-first quarter of 2019. Out of the eight years surveyed, in terms of volume ATM has seven while NIP has one and it is on the first quarter of 2019. In terms of value NEFT dominated in 2012 and 2013 while NIP dominated from 2014 to first quarter of 2019. Although, the system (e-payment) is challenged security, infrastructures, legal and regulatory issues as well as socio-cultural issues [17], it is recommended that more electronic channels should be open to deepen the electronic transactions in the economy to fast tract transaction as the world move into tech revolution. Also, the issue of fraud emanating from electronic transaction should be checked and reduced to give trust to consumers of such transactions. Lastly, banks must perform more education and advertisement on electronic payments so that the Nigerian population will appreciate and use electronic payment channels available.

\section{References}

[1] Ojo, J. A. T. (1998). Improving the Nigerian payment system: Prospects and promises. Nigerian Journal of Banking and Financial Issues, 1 (1) 39-47.
[2] Okifo, J., \& Igbunu, R. (2015) Electronic Payment System in Nigeria: Its Economic Benefits and Challenges. Journal of Education and Practice 6. (16) 56-62.

[3] Kelvin, O. (2012). Mobile Money for Financial Inclusion. Journal of Macro Finance, Africa, Nett, Lagos. 4: 14.

[4] Damkwambo, I. H. (2009). Understanding the e-payment system in Nigeria. Paper at the workshop on in Abuja, 30th March.

[5] Okafor, P. (2017). Electronic payment/transactions: Epayment in Nigeria. Online: http:/www.naijatechguid.com/

[6] Ayodele, T. D. (2014). Electronic banking in Nigeria: Challenges and prospects. Elixir International Journal of Finance management, 69, (22912-22915).

[7] Oladayo, T. \& Adeniyi, O. (2014). Automated Teller Machine Fraud in South West Nigeria: The shoe wearers perspectives, Nigerian Tribune, Ibadan, P. 2.

[8] Ayodele, T. (2015). Nigeria payment systems through electronic banking: A review. International Journal of Transformations in Business management. 5 (11) 27-33.

[9] Okafor, L., (2008) Nigeria payments system: The role of the banking industry. Paper Presented at the CBN Seminar on the Dynamics of Managing the Nigeria Payment System in the 21st Century.

[10] Osang, F. B. (2017) E-banking: evaluating electronic payment channels in southern Nigeria. NOUN Journal of Physical and Life Sciences 1: 135-157.

[11] Osibote, I. I. (2010). E-payment system: processes, procedures, challenges and prospects. Paper at workshop on in Abuja, 15th March. Online: http://financial.tmcnet.com//mergeracquisitions/news/2010//8 5073144.htm.

[12] National Bureau of Statistics, (2012). Annual Statistical Reports, 13: 11.

[13] National Bureau of Statistics, (2016) Electronic payment channels in the Nigeria banking sector Q3, Abuja, NBS.

[14] Central Bank of Nigeria (2019) E-Payment Statistics. Abuja, $\mathrm{CBN}$.

[15] National Bureau of Statistics, (2018) Selected banking sector data: Sectorial breakdown of credit, ePayment channels and staff strength. Abuja, NBS.

[16] First Bank of Nigeria (2018) Nigeria's electronic payment channels in 2018. Research Weekly 8 (12) 1-5.

[17] Ayo, A. O. (2011). Emergence of Payment Systems in the era of e-commerce in Nigeria: Problems and Prospects. Delta Business Education Journal, 1 (6), 64-72. 